IZA DP No. 4519

Labor-Market Exposure as a Determinant of Attitudes toward Immigration

Francesc Ortega

Javier G. Polavieja

October 2009 


\title{
Labor-Market Exposure as a Determinant of Attitudes toward Immigration
}

\author{
Francesc Ortega \\ Universitat Pompeu Fabra \\ and IZA
}

Javier G. Polavieja

IMDEA Social Sciences

\section{Discussion Paper No. 4519 \\ October 2009}

\author{
IZA \\ P.O. Box 7240 \\ 53072 Bonn \\ Germany \\ Phone: +49-228-3894-0 \\ Fax: +49-228-3894-180 \\ E-mail: iza@iza.org
}

\begin{abstract}
Any opinions expressed here are those of the author(s) and not those of IZA. Research published in this series may include views on policy, but the institute itself takes no institutional policy positions.

The Institute for the Study of Labor (IZA) in Bonn is a local and virtual international research center and a place of communication between science, politics and business. IZA is an independent nonprofit organization supported by Deutsche Post Foundation. The center is associated with the University of Bonn and offers a stimulating research environment through its international network, workshops and conferences, data service, project support, research visits and doctoral program. IZA engages in (i) original and internationally competitive research in all fields of labor economics, (ii) development of policy concepts, and (iii) dissemination of research results and concepts to the interested public.
\end{abstract}

IZA Discussion Papers often represent preliminary work and are circulated to encourage discussion. Citation of such a paper should account for its provisional character. A revised version may be available directly from the author. 
IZA Discussion Paper No. 4519

October 2009

\section{ABSTRACT \\ Labor-Market Exposure as a Determinant of Attitudes toward Immigration*}

This paper re-examines the role of labor-market competition as a determinant of attitudes toward immigration. We claim two main contributions. First, we use more sophisticated measures of the degree of exposure to competition from immigrants than previously done. Specifically, we focus on the protection derived from investments in job-specific human capital and from specialization in communication-intensive jobs, in addition to formal education. Second, we explicitly account for the potential endogeneity arising from job search. Methodologically, we estimate, by instrumental variables, an econometric model that allows for heterogeneity at the individual, regional, and country level. Drawing on the 2004 European Social Survey, we obtain three main results. First, our estimates show that individuals that are currently employed in less exposed jobs are relatively more proimmigration. This is true for both our new measures of exposure. Second, we show that the protection granted by job-specific human capital is clearly distinct from the protection granted by formal education. Yet the positive effect of education on pro-immigration attitudes is greatly reduced when we control for the degree of communication intensity of respondents' occupations. Third, OLS estimates are biased in a direction that suggests that natives respond to immigration by switching to less exposed jobs. The latter finding provides indirect support for the endogenous job specialization hypothesis postulated by Peri and Sparber (2009).

JEL Classification: F1, F22, J61, J31, R13

Keywords: immigration attitudes, labor market, job-specific human capital, communication skills, international migration

Corresponding author:

Francesc Ortega

Department of Economics and Business

Universitat Pompeu Fabra

Ramon Trias Fargas 25-27

08005 Barcelona

Spain

E-mail: francesc.ortega@upf.edu

\footnotetext{
* Authors appear in alphabetical order. Research for this paper has been supported by the INSIDE Project (Insights on Immigration and Development, www.inside.org.es), which is financed by the Institute for Economic Analysis, IAE-CSIC. A previous version of this paper was presented at the conference Economic Incorporation, Spatial Segregation and Anti-Immigrant Sentiments hosted by the Juan March Institute of Study and Research. We thank all the conference participants for their helpful comments and, in particular, Andrew Richards for his insightful discussion of the paper. We also wish to thank Catalina Amuedo-Dorantes and Sara de la Rica for sharing their occupation cross-walks with us.
} 


\section{Introduction}

Over the last decade a great deal of research has been devoted to analyzing the economic determinants of attitudes toward immigration. Special attention has been paid to testing the hypothesis that competition with immigrants in the labor market influences native workers’ views. $^{1}$

The degree of competition between native and immigrant workers is defined by their relative skills. In most studies skills are measured using education levels. Under the assumption that immigrants are, on average, less educated than natives, it is expected that low-educated natives oppose immigration to avoid depressing their wages. In contrast, being less exposed to competition from immigrants, highly-educated natives should hold less negative views toward (low-educated) immigration and could even be in favor of it,

depending on the elasticity of the supply of capital. Typically, most studies have found a positive association between respondents' educational attainment and their pro-immigration views. This association has been interpreted as evidence that labor-market competition has indeed attitudinal effects.

We find such interpretation wanting for the following two reasons. First, it must be noted that the observed relationship between education and attitudes toward immigration does not constitute by itself unequivocal evidence in favor of the labor market exposure hypothesis since mechanisms other than competition could be driving this association. Sociologists and political scientists have long been putting forward alternative interpretations of the attitudinal effects of education (see e.g. Jackman and Muha 1981, Bobo and Licari 1989, Burns and Gimpel 2000, Kingston et al. 2003). They have argued that the positive effect of education on pro-immigration attitudes could be entirely due to values and predispositions that are associated to schooling, such as tolerance, open-mindedness or political correctness, rather than to relative scarcity of human capital (see also Wagner and Zick 1995; Hainmueller and Hiscox 2007, Côté and Erickson 2009).

\footnotetext{
${ }^{1}$ Mayda (2006) provides a useful brief overview of the relevant literature.
} 
Secondly, and most importantly, we believe that defining skills solely in terms of years of education constitutes a very narrow definition of the human-capital resources that characterize native-immigrant competition in the labor market and hence provides an incomplete test for the labor-market exposure hypothesis.

The main goal of our paper is to provide a re-examination of the role of labor-market exposure to competition as a determinant of attitudes toward immigration. The key feature in our analysis is that we consider a more comprehensive definition of skills than previously used in the literature. Whilst most studies define skills using educational levels only - typically distinguishing between college-graduates and workers without tertiary education-, we consider two further measures of skills influencing the degree of exposure to labor-market competition. These new measures are directly linked to the characteristics of the tasks workers perform at their jobs. From an empirical point of view, an attractive feature of these measures is their large variation, across jobs and occupations.

The first new measure of labor-market exposure we consider is job-specific human capital. Workers acquire job-specific skills at their firms via formal training, informal instruction or learning-by-doing. Investing in job-specific skills makes workers less replaceable, regardless of their level of education (Becker 1993[1964], Lazear 1995). Job-specific human capital thus provides protection against competition from other workers, native and immigrant alike.

Our second measure of labor market exposure is motivated by recent work studying how native workers respond to recent immigration. Peri and Sparber (2009) show that when immigrants arrive into an economy, native workers mitigate the wage effects of immigration by shifting toward occupations for which they have a comparative advantage. Specifically, immigration induces native workers to shun manual jobs and specialize in communication-intensive occupations. Natives' comparative advantage in such occupations stems from the possession of those skills that immigrants typically lack, in particular, language and/or cultural-specific skills. We hypothesize that native workers in communication-intensive (manual) occupations will be more (less) protected from 
immigrants' competition and hence will be more (less) likely to display pro-immigration attitudes. $^{2,3}$

By estimating directly the attitudinal effects of respondents' general, job-specific and communicational skills, we attempt to cover all the skill dimensions of labor-market competition. To our knowledge, ours is the first paper that provides such a comprehensive test for the exposure hypothesis.

Another attractive feature of our analysis is the use of individual-level data for many countries, as in Mayda (2006). Our main data source is the 2004 European Social Survey. The immigration module in this dataset has several unique features. It contains detailed questions that are highly relevant to understanding individual opinions on immigration. In addition, identical questions are posed to all countries included in the survey, allowing for high quality cross-country comparisons. ${ }^{4}$ For our purposes, another attractive feature of the data is that it identifies the respondents' region of residence within the country. Following Autor, Levy and Murnane (2003) and Peri and Sparber (2009), we also use the US Occupational Network Online Dataset $\left(\mathrm{O}^{*} \mathrm{NET}\right)$ to build measures of the intensity of interactive (and manual) tasks by occupation.

Methodologically, we estimate an econometric model that allows for heterogeneity at the individual, regional, and country level. The dependent variable is a measure of the respondent's views toward immigration and we consider three dimensions of skills that determine these views: formal education, required job-learning time at the current job net of education (that is, job-specific human capital) and communication-intensity of the current occupation. Each of these skill variables measures a distinct source of protection from immigrant competition in the labor market. We expect lower exposure in each dimension to be associated with more favorable immigration attitudes.

\footnotetext{
2 Supply constraints or job searching costs may limit the number of native workers that can shift from manual to communication-intensive occupations.

${ }^{3}$ Peri and Sparber (2009) use data for the US. Amuedo-Dorantes and De la Rica (2009) conduct a similar study using data for Spain and focusing on gender differences.

${ }^{4}$ Card, Dustmann and Preston (2005) provide a detailed overview of the immigration module in the 2002 European Social Survey.
} 
A further contribution of our study is our treatment of individual heterogeneity. Our analysis explicitly accounts for heterogeneity among natives in their views toward immigration and for potential self-selection into low-immigration jobs. Individual observable heterogeneity is addressed by estimating specifications that include a vector of controls for ideological and attitudinal variation, whilst self-selection is addressed by using an instrumental-variables approach. Specifically, we use the regional availability of lowexposure jobs as an instrument for actual individual exposure in the current job. To our knowledge, building an instrument for individual labor market exposure is novel in the literature. $^{5}$

Overall, our results suggest a larger role for labor market competition as a determinant of individual attitudes toward immigration than previously found, as well as a new interpretation for the positive association between education and pro-immigration attitudes. More specifically, we report the following three main findings.

First, the limited role for labor market competition in earlier studies may have been due to a combination of poor skill indicators and endogeneity problems. Our estimates suggest that individuals with above-average dislike for immigrants tend to work in low-immigration jobs, biasing OLS estimates downwardly.

Second, our instrumental-variables estimates show that individuals employed in less exposed jobs are relatively more pro-immigration. This is true for our two new measures of exposure. Both the amount of specific human capital required by the job as well as the type of skills required in any given occupation play a crucial role in shaping attitudes toward immigration. This finding provides indirect evidence in support of the mechanism in Peri and Sparber (2009). Namely, it is consistent with the prediction that unskilled natives will

\footnotetext{
5 Endogeneity concerns of the type addressed here are also at the heart of the analysis of Dustmann and Preston (2001). They are interested in the effects of ethnic geographical concentration at the local level on individual attitudes toward immigration. To that effect they build an instrument for local ethnic concentration using regional data.
} 
shift away from jobs and occupations where they face greater competition from immigrant workers.

Third, the positive effect of formal education on pro-immigration attitudes is orthogonal to job-specific human capital but it is greatly reduced when we control for the level of communication-intensive (manual) tasks in the current occupation. This suggests that, to some extent, education is a proxy for the type of occupation.

The paper is organized as follows. Section 2 situates this paper in the context of the previous literature. Section 3 presents the data sources, definitions of variables and descriptive statistics. Section 4 introduces our estimation method and explains how we deal with endogeneity. The main findings are presented in Section 5. Sensitivity analyses are reported in Section 6. Section 7 concludes.

\section{Previous literature}

Our paper is part of a large and growing body of literature analyzing the determinants of attitudes toward immigration. We can classify the work that is more directly related to our analysis in three main groups.

First, several authors have attempted to quantify the contribution of labor market considerations relative to welfare state considerations and to non-economic factors in explaining attitudes toward immigration. Using factor analysis, Dustmann and Preston (2005) analyze the determinants of immigration attitudes using the 2002 European Social Survey. With a similar methodology, Dustmann and Preston (2007) use data for Great Britain. To identify the role of labor market concerns they employ survey questions on fear of job loss, ease of finding a job, and expected future earnings. The results are similar in both cases. They find that subjective labor market concerns are a significant determinant of attitudes toward immigration. However, fiscal considerations and cultural and racial concerns seem to play a larger role. We note that their labor market variables are not directly related to exposure to competition from immigrants. 
Our paper is also related to a large empirical literature examining the relationship between individual education levels and attitudes toward immigration. The common finding across all papers listed below is that more educated individuals are more pro-immigration, a finding that is typically interpreted as evidence in favor of the labor-market competition hypothesis. Among the early studies, Espenshade and Hempstead (1996) and Scheve and Slaughter (2001) use data for the US, while Dustmann and Preston $(2001,2005)$ study the UK. More recently, Mayda (2006) and O'Rourke and Sinnott (2006) have employed individual-level data covering several (mostly rich) countries. Mayda (2006) shows that education is more strongly associated to pro-immigration attitudes in countries with higher GDP per capita. She provides a labor-market interpretation for her finding, which is consistent with the factors proportion model. O'Rourke and Sinnott (2006) find a similar result. They also find that non-economic considerations play a larger role than labor market concerns. Facchini and Mayda (2009) study empirically the joint relationship between individual income and education and attitudes toward immigration. They find that in countries with relatively unskilled immigration, individual income is negatively correlated with pro-immigration preferences, while education has a positive effect. They propose a model with endogenous income redistribution that can rationalize this pattern. ${ }^{6}$

Finally, in addressing endogeneity in the analysis of attitudes toward immigration our paper connects to the work of Dustmann and Preston (2001) on the effects of ethnic geographical concentration at the local level. These authors argue that the residential choices of immigrants (and natives) are likely to depend on unobserved determinants of individual attitudes. They propose an instrumental-variables approach, where county-level ethnic composition is used as an instrument for neighborhood ethnic composition. Controlling for endogeneity, they find that higher ethnic residential concentration leads to worse attitudes toward immigration among natives. Their results suggest that ignoring the endogeneity problem leads to underestimating this attitudinal effect, since it appears that natives that dislike immigrants tend to locate in low-immigration localities.

\footnotetext{
${ }^{6}$ Another theoretical model analyzing the determination of attitudes toward immigration in the presence of an endogenously determined welfare state is Ortega (2009).
} 


\section{Data}

\subsection{Sources}

Our main data source is the 2004 European Social Survey (ESS). It contains information on over 47,000 individuals from 25 countries. All countries with the exception of Luxemburg and Iceland are subdivided into regional units (273 regions). Most countries are 3-4\% of the total sample each, amounting to roughly 1,300 observations each. The mean number of observations per region is 76 and the median is $53 .^{7}$ Both the cross-country and the crossregion, within-country variation will be important in our analysis. We restrict our sample to currently employed individuals in age bracket 18-64 who are citizens in the respective country of residence in 2004. The resulting sample contains over 20,000 individuals.

We also use data from $\mathrm{O}^{*} \mathrm{NET}$, which provides a detailed description of the characteristics of each occupation in the US. The O*NET dataset is developed under the sponsorship of the US Department of Labor/Employment and Training Administration. The O*NET dataset provides very detailed information of the mix of knowledge, skills and abilities required, as well as the activities and tasks typically performed, in 449 different occupations. O*NET provides 277 descriptors for each occupation. Each descriptor consists of a score ranging from 0 to 1 for each dimension of skill or ability considered. These scores are collected by occupation analysts and are constantly updated by ongoing surveys of each occupation's worker population and external occupation experts. We use O*NET skill descriptors to construct two measures of occupation-specific skills relating to labormarket competition between natives and immigrants. The first measure is an index of the amount of communicational (or interactive) skills required in each occupation, whilst the second measures the amount of physical (or manual) skills. These measures are subsequently matched to European occupational data under the assumption that occupations

\footnotetext{
${ }^{7}$ Appendix 1 contains a list of countries with the number of individual observations per country.
} 
across US and European economies do not differ in relation to these two basic skill dimensions (see below). ${ }^{8}$

\subsection{Definitions}

In line with the existing literature, our dependent variable measures respondents' desired levels of immigration in their countries. The ESS contains three related questions. In each question, the respondent is asked whether more immigrants of a particular origin should be allowed in the country. There are four possible responses: none, a few, some, or many. The three related questions differ on the origin of immigrants: the same race/ethnic group as the current majority in the population, a different race/ethnic group or from poorer countries outside Europe.

Our main dependent variable (IM1) is a simple transformation of the question referring to the desired level of immigration of individuals belonging to the same ethnic group as the current majority. We re-scale the variable so that it ranges from 0 to 100 , where higher numbers mean higher support for immigration (i.e. lower entry restrictions). Our new variable takes 4 values: 25 (none), 50 (a few), 75 (some), and 100 (many). We note that this question can be interpreted as the respondent's views on how immigration affects his or her individual outcomes. By leaving ethnicity considerations aside, we believe that this variable is better equipped to capture the economic determinants of attitudes toward immigration. Yet we also analyze whether our main results are robust to variations in the definition of our dependent variable.

One of our main explanatory variables is a measure of the specific human capital required by the respondent's job, measured as job-learning time for individuals with the appropriate educational credentials. We note that this is a subjective measure as it is based on respondents' self-assessments, yet the very wording of the question is such that minimizes self-reporting bias. Specifically, the ESS asks respondents: "If someone with the right

\footnotetext{
${ }^{8}$ For more details see http://online.onetcenter.org/.
} 
education and qualifications replaced you in your job, how long would it take for them to learn to do the job reasonably well?". We note that the question clearly differentiates between general and job-specific human capital. The original question allows for eight possible answers, detailing intervals of time expressed in days, weeks, months or years. Based on this information we create a numerical variable expressed alternatively in days or months that can be used in a regression framework. We shall denote our variable by SHK (specific human capital). SHK has a mean of 265 days or, equivalently, 8.8 months. Interestingly, the correlation with education is positive but very low (0.13). This suggests that the wording of the question may indeed allow us to disentangle the effect of education from the effect of job-specific human capital on immigration views.

We also use a second set of variables to measure workers' degree of protection to labor market competition from immigrants. Following Peri and Sparber (2009), we assume that natives are better at communicational or interactive (relative to manual) tasks than recent immigrants. As explained-above, our measures of communication and manual skills were constructed using the $\mathrm{O}^{*} \mathrm{NET}$ dataset. We proceeded as follows: first, we used exploratory factor analysis to identify our skill dimensions of interest out of the 277 descriptors available in the dataset. Informed by this analysis, we constructed two different measures capturing the skill dimensions of interest. Measure 1 is an index that tells us how communicational-intensive a particular occupation is. For each occupation of the dataset, this index simply averages the scores rating the task-importance and the mean observed abilities of 6 different communicational skills previously identified by factor analysis as part of the same skill dimension. These skills are: oral comprehension, oral expression, written comprehension, written expression, speech recognition, and speech clarity. Measure 2 captures, in turn, how important physical skills are in each occupation by averaging the task-importance and observed ability scores of the following 7 descriptors: visualization, arm-hand steadiness, manual dexterity, finger dexterity, control precision, wrist-finger speed and visual color discrimination. 
These two indices are then matched to ISCO-88 occupations using the same occupational crosswalk employed by Amuedo-Dorantes and De la Rica (2009). ${ }^{9}$ Further details on the construction and merging of $\mathrm{O}^{*} \mathrm{NET}$ scores can be found in the Appendix. In the O*NET dataset the two indices (manual and communication intensities) are strongly negatively correlated, with a coefficient of correlation equal to -0.54. In the ESS data the correlation goes up to $-0.78 .^{10}$ This very high correlation implies that, effectively, both variables contain the same information: the degree of communication-intensive relative to manual tasks required by each occupation. Throughout the analysis we focus on the measure of communication intensity. In the robustness section we will also use the index of manual skills. Note that, implicitly, we are assuming that the skill requirements in US occupations are the same as the skill requirements in the same occupations in Europe. While it would certainly be a stretch to make this assumption for all the occupational descriptors included in $\mathrm{O}^{*} \mathrm{NET}$ or if we were comparing countries with widely different levels of economic development, we believe it is a reasonable assumption in the context of our analysis.

\subsection{Descriptive statistics}

Let us now provide a brief description of the main variables in our analysis. We start with the dependent variable: a measure of the respondent's desired level of immigration of people of the same ethnicity as most of the population in the country (IM1). Appendix 2 contains the exact wording of the question. Appendix 3 reports some summary statistics. The modal score is 75 , with $46 \%$ of the sample, and a total of $68 \%$ supporting some more or many more immigrants of the same ethnicity. As for the rest of the sample, $25 \%$ think that only a few more immigrants should be admitted and about $7 \%$ of the population think no more immigrants should be allowed into their countries. The mean response across all countries (score 70.9) is very close to “allow some more immigrants.” However, it is

\footnotetext{
9 The authors are most grateful to Sara De La Rica and Catalina Amuedo Dorantes for kindly making their crosswalk available to us.

10 The main reason for the increase in correlation is that the $0^{*}$ NET-ESS crosswalk only allows us to match 3-digit $\mathrm{O}^{*} \mathrm{NET}$ occupational codes into 2-digit ISCO-88 occupations.
} 
interesting to note that there is substantial variation across countries. Table 1a presents the mean values for the 25 countries. For Portugal, Turkey, Greece, and the Czech Republic the mean ranges from 56 to 64 (roughly, allow a few immigrants to enter). At the other end of the spectrum, Sweden, Ukraine and Iceland are the more pro-immigrant, with mean values in the 80-86 range. The second column in Table 1a reports attitudes toward immigration that are ethnically different to the majority of the population in the destination country. Clearly, pro-immigration attitudes are lower (average score 65) than for the case of immigrants with the same ethnicity as the majority of the population (average score 71). However, we note that the values in column 2 are approximately increasing as we move down the table, suggesting that the ranking of countries is practically the same for the two measures of attitudes toward immigration. We shall use this variable in our robustness section.

Let us now turn to the main explanatory variables. To relate to earlier literature it is helpful to begin by reviewing the data on years of education. As shown in column 3, the mean across all countries is 12.7 years, but the data display a larger variation, ranging from 8.7 (Turkey) to 14.4 (Denmark) years of education. Again we note that the values in column 3 are generally increasing as we move down the list, even though the relationship is not very strong. This illustrates that the positive association between pro-immigration attitudes and years of schooling is not only found across individuals within a country but also across countries.

Next, let us examine our measure of job-specific human capital. The mean value across all countries for how much time is needed for someone with the right qualifications to replace a worker is 8.9 months (Table 1a). Again we observe substantial cross-country variation, ranging from 3.9 (Portugal) to 13.2 months (France), as illustrated by Table 1a. As we noted earlier, our measure of job-specific human capital is only weakly correlated with years of education. The correlation coefficient is 0.13 .

We now turn to the indices of the communication and manual skill requirements by occupation. By construction, these indices take values between zero and one. Across countries the mean value for the communication skills index ranges from 0.36 in Turkey or 0.38 in Poland to 0.54 in the Netherlands, with a mean value of 0.45 . The manual skills 
index has a significantly shorter range, taking values between 0.48 (Netherlands) and 0.58 (Poland). We also note that the top of the ranking by communication skills coincides with the bottom by manual skills, and vice versa. As we discuss later, the correlation coefficient between these two variables is very close to minus one.

Table 1b presents descriptive statistics for all the relevant variables for our main sample of individual observations. In the sample, immigration attitudes (IM1) range between 25 and 100 , and years of education range from 0 to 25 . Crucial to our identification strategy, there is high variation across individuals in job-specific human capital (SHK), and communication and manual skills. In terms of correlations, years of education is positively correlated with communication skills and negatively with manual skills. In turn, the communication skills index is positively correlated with job-specific human capital but this correlation is weak (correlation coefficient 0.15 ). Manual dexterity is not correlated with job-specific human capital (-0.02). The Table also reports a number of individual-level variables that we will use to control for (observable) individual heterogeneity in immigration views. These variables are dummy variables for the presence of children in the house, for living in a rural area, for having a foreign-born mother, and a vector of individual attitudes and perceptions, including ideology, religiosity, happiness, trust, and social capital.

To provide some insight into what is captured by our measures of communication and manual skills, we next compare the samples of individuals currently employed in communication-intensive occupations (75 percentile) to those in manual-intensive occupations (75 percentile). We find that, on average, manual workers have 2.6 fewer years of education, and 77 fewer days of job-learning time.

Furthermore, Table 2 reports the top 10 occupations ranked by their average years of schooling, average job-specific human capital (job-learning time), average communicational intensity scores and average manual intensity scores. Two features are worth noting. First, several of the top occupations by educational attainment are also in the top ranking by communicational skills. For instance, medical doctors and biologists (life and health professionals), mathematicians and physicists, or higher-education teaching professionals appear in both lists. Second, the overlap is much smaller between the top 
occupations by educational attainment and by job-specific human capital. In fact the latter contain several occupations that do not require much formal education, such as "riggers and cable splicers”, “wood processing and paper-making plant operators”, or “upholsterers”. This observation suggests that specific and general human capital (in the form of years of education) are indeed two separate dimensions of labor market exposure.

\section{Estimation}

\subsection{Econometric model}

Our dependent variable is a measure of individual views on immigration. Specifically, $\operatorname{IM}(i, r, c)$ is the response of individual $i$ living in region $r$ and country $c$ to the question of whether immigration should increase or decrease. Our model attempts to explain individual variation in this variable employing several models of the form:

$$
I M_{i, r, c}=\alpha_{c}+\beta_{1} S H K_{i, r, c}+\beta_{2} \operatorname{Comm}_{i, r, c}+\gamma y e d u_{i, r, c}+\delta x_{i, r, c}+\varepsilon_{i, r, c}
$$

where the right-hand side contains country-specific intercepts, our new measures of exposure (job-specific human capital and communication skill requirements in the current occupation), years of education, and a set of controls. ${ }^{11}$ The vector of controls always includes, age, age squared, gender, and dummies for the presence of children in the household, living in a rural area, and having a foreign-born mother. Occasionally, we will also introduce a set of additional variables aimed at capturing individual heterogeneity that may be relevant to understand the respondent's views on immigration (ideology, religiosity, happiness, trust, and social capital). ${ }^{12}$ For short we shall refer to this latter set of variables as individual attitudes. Finally, we allow the error term to be correlated across individuals living in the same region.

11 In principle it would be possible to include region-specific intercepts. We shall do so in one of our OLS specifications. However, given the definition of our instrument, only country-specific intercepts can be included in our instrumental-variables specifications.

12 We are aware that some of these attitudinal variables may be endogenous. To evaluate this concern we will estimate all our main specifications with and without the vector of attitudes. 
As argued above, together with general skills, job-specific human capital and communicational skills should provide protection against labor-market competition from immigrants. Hence we expect the coefficient on years of education $(\gamma)$ and on our two additional measures of labor market protection to immigration $\left(\beta_{1}\right.$ and $\left.\beta_{2}\right)$ to be positive.

\subsection{Endogeneity}

We are concerned with the following endogeneity problem. Individuals that particularly dislike immigration will search more intensively for jobs with few immigrants. These jobs will tend to display a high degree of protection from competition from immigrants. As a result, OLS estimates of our coefficients of interest ( $\beta_{1}$ and $\left.\beta_{2}\right)$ are likely to be downwardly biased.

Our strategy to deal with this endogeneity problem is to use instrumental variables. Specifically, we postulate that individuals living in a region where there is a high availability of highly protected jobs are more likely to end up in one of these jobs than a comparable individual in a region where protected jobs are scarce. Thus we propose to use a measure of the regional availability of protected jobs as an instrument for the degree of protection in an individual's job. In particular, we instrument an individual's level of job protection by the mean protection of the average worker in his or her region of residence. Implicitly, our approach assumes that natives do not sort into regions (or countries) based on their views on immigration. ${ }^{13}$ Similarly, and in line with the literature, we also assume that educational attainment is not determined by one's views over immigration.

Let us now examine the relevance of our instrument. Table 3 reports the results of the firststage regressions. We report several specifications, varying in the dependent variable. In column 1, the dependent variable is SHK, our measure of job-specific human capital. The right-hand side of the regression contains country-specific dummies, a series of controls (not shown in the Table) that include years of education, and the average value of SHK in

\footnotetext{
13 There is little evidence of displacement of natives in response to immigration in US data (Card and DiNardo 2000, Card 2001) or in European data (Gonzalez and Ortega, 2009).
} 
the respondent's region of origin. Standard errors are heteroskedasticy-robust and have been clustered at the region level. The point estimated of the variable of interest is 0.92 , very precisely estimated and with a t-statistic of 47.99. In words, individuals residing in a region with a large availability of jobs requiring high specific human capital are more likely to end up in such jobs, provided that they have the right education level.

Columns 2 and 3 report analogous regressions where the dependent variables are, in turn, our measures of communication skills and manual skills. As expected, the main coefficient is positive and highly significant in both cases. In addition, the values of the F-statistics imply that we can clearly reject the null hypothesis of weak instruments. Columns 4 through 6 report the first-stage regressions that correspond to our specifications including two endogenous measures of exposure at a time. Again, the results suggest that our instruments are strong.

Finally, we perform a robustness test on the strength of our instruments. We drop all regions with fewer than 25 observations (less than 5\% of the total sample of individuals). The bottom panel of Table 3 shows that the first-stage estimates are virtually unchanged and the F-statistic associated to the null hypothesis of weak instruments remains very high.

\section{Main results}

\subsection{Job-specific human capital}

We are interested in testing the following hypothesis. Individuals employed in jobs characterized by high requirements of specific human capital hold more favorable views on immigration. This is because job-specific skills protect insider native workers from outside competition. To test this hypothesis we estimate the regression model described in equation (1). The dependent variable is a measure of the respondent's pro-immigration views (IM1). The right-hand side of the model contains country (or region) fixed effects, the degree of job-specific human capital in the worker's current job, years of education, and a number of controls. We cluster standard errors at the regional level. 
Table 4 presents the OLS (columns 1-4) and IV estimates (columns 5 and 6). As a benchmark, column 1 reports the OLS estimate of a regression where attitudes toward immigration are solely a function of years of education and individual controls. As expected, the education coefficient is positive and quite large (1.07). We also note the negative coefficients on the female, children, and rural dummies, and the large and positive effect of having a foreign-born mother. The following columns include the main explanatory variable, job-specific human capital. The OLS estimate is small and we cannot reject a value of zero (columns 2-3). Column 4 includes region fixed effects, which hardly affect the estimates obtained in column 3.

Column 5 presents our preferred specification for the IV estimation. We find that individuals employed in jobs characterized by high job-specific human capital are more pro-immigration. The effect is quite large and statistically significant (p-value 0.053). An increase in four months in the time required to learn job-specific skills (conditional on education) has roughly the same effect on attitudes toward immigration as one additional year of education. In this sense, the marginal effect is three times larger for specific-human capital than for years of schooling. It is worth noting that the effect we have uncovered is distinct from the effect of educational attainment. The IV estimate of an additional year of education is 0.94 , which is not statistically different from its OLS estimate. Finally, column 6 presents an additional IV specification including the vector of attitudinal variables. These additional controls reduce by roughly $10 \%$ the effect of education but do not affect our estimate of the effect of job-specific human capital.

We also note that our results suggest that OLS estimates of the effect of specific human capital were downwardly biased, as we had expected. Our interpretation is that individuals who dislike immigrants search more intensively for jobs that are highly protected from immigration. As a result individuals sort into jobs that, given their qualifications, require higher job-specific human capital. The endogeneity bias that we uncover is similar to the one documented by Dustmann and Preston (2001). Their results suggest that individuals sort spatially according to their attitudes toward minorities. 


\subsection{Communicational skills}

Job-specific human capital provides protection toward all outsiders to the job, natives and immigrants alike. Here we try to be more specific and focus on a characteristic that only offers protection toward recent immigrants, but not toward natives or immigrants that are already well established and have fully assimilated. Building on Peri and Sparber (2009), we assume that natives have comparative advantage in communication-intensive tasks relative to recent immigrants. Hence, we hypothesize that individuals employed in communication-intensive occupations will be relatively more pro-immigration. Conversely, individuals employed in eminently manual occupations are expected to be relative less proimmigration. We stress that our identification is based on comparisons across individuals within a country, holding education levels and other relevant demographic characteristics constant.

To analyze this question we estimate the model in equation (1) but we now use measures of the communication skill-requirements of respondents' current occupations. The results are presented in Table 5. Columns 1-4 report OLS estimates. Note that the estimate of years of education ranges between 0.61 and 0.74 after introducing our index of communication intensity. This is around 30\% lower than in the previous section. In turn, the point estimate associated to communication skills is positive and significant, with values around 10 . Columns 5 and 6 present our IV estimates. As was the case for job-specific human capital (Table 4), IV estimates of the measure of protection are substantially higher than OLS estimates, with a value of 27.06 in column 5. A simple calculation shows that an increase in the communication skills index of one standard deviation (0.22, Table 1b) leads to a 6-point increase in the immigration opinion index. Column 6 shows that controlling for individual values and attitudes reduces further the effect of education but does not affect our estimate of the effect of communication skills. Finally, we also point out that years of education is not significant in our IV estimates. This suggests that the effect of education on attitudes toward immigration could stem from its correlation with communication skills. 


\subsection{Education, job-specific human capital, and communicational skills}

As discussed in the Introduction, most previous studies have focused on a single measure of human capital, namely, years of education. An important feature of our analysis is that we have considered several dimensions of skills. In the previous sections we have found that both job-specific human capital and communication skills are important determinants of individuals' attitudes toward immigration.

The goal of this section is to analyze the interaction between our two new measures of labor-market exposure and years of education. Table 6 presents the instrumental-variables estimates. As a benchmark, column 1 includes only years of education as explanatory variable (in addition to the demographic controls). The point estimate on years of education is 1.066. Including job-specific human capital (column 2) reduces the coefficient on education only slightly, suggesting that job-specific and general human capital (education) have differentiated effects on immigration views. The point estimate of SHK is 0.22 and the associated standard error is 0.12 (that is, a p-value of 0.053). As argued in the previous section, the effect of job-specific human capital is roughly three times larger than that of education, when both are measured in the same time units. ${ }^{14}$ Column 3 adds our measure of communication skills. The coefficient on job-specific human capital remains practically unchanged (0.21) but the coefficient on years of education drops dramatically (0.23) and becomes not statistically different from zero. Column 4 adds the vector of individual attitudes. The effect of education drops even further (0.09) whereas the coefficient on SHK remains practically unchanged (0.20). Finally, column 5 replaces communication skills with manual skills. The results confirm the message of the previous column. Naturally, the estimated effect of manual skills on pro-immigration attitudes is negative and highly significant, indicating that workers employed in occupations that require high levels of manual dexterity - and hence where competition with immigrants is greater - report relatively more negative attitudes toward immigration. The effect of education remains low (and insignificant) and the point estimate for SHK increases slightly (0.23), strengthening the rejection of the null hypothesis of a zero coefficient (p-value of 0.044).

\footnotetext{
${ }^{14}$ Recall that SHK is measured in months whereas education is measured in years.
} 
In conclusion, the two measures of protection toward immigration that we have analyzed (job-specific human capital and communication skills) are both found to have significant and distinct effects on individual attitudes toward immigration. Our results also suggest that the effect of education on attitudes operates mainly through occupational attainment, since formal education allows access to occupations that are protected from labor-market competition with immigrants. These occupations require high communicational skills.

\section{Robustness}

We now conduct some sensitivity analysis on our main results. Specifically, we make use of two alternative definitions of attitudes toward immigration, we re-estimate our main models on subsamples that differ in the level of education, and we experiment with substituting the measure of communication skills by the measure of manual skills.

Table 7 reports our findings. To provide a benchmark for comparison, column 1 displays the estimates from specification 3 in Table 6. Column 2 uses manual skills as a measure of comparative advantage with respect to immigrants. As noted previously, the education coefficient is drastically reduced when the regression includes either manual or communication skills. In contrast, the coefficient of job-specific skills remains largely unaltered.

Columns 3 and 4 use two alternative measures of the respondent's views toward immigration. Dependent variable IM2 is the simple average between the three questions available in the European Social Survey regarding the desired level of immigration. These questions differ on the geographic origin of the immigrants. ${ }^{15}$ The point estimate on SHK falls a bit but remains significant at 10\%. Column 4 uses IM3 as dependent variable. This variable is again an average of three questions on immigration. However, these questions differ from those used in IM1 and IM2 in one key aspect. The questions used in IM3 are much broader, and report on the respondents' views on the effects of immigration on their

\footnotetext{
${ }^{15}$ For more details, please see questions A1-A3 in Appendix 2.
} 
country's economy, culture, and life in general. ${ }^{16}$ Note that this wider frame of reference could make responses to these questions less sensitive to individuals' degree of labormarket exposure. That is to say, a protected worker and an exposed one could very well agree on the effects of immigration on the economy as a whole or on the country's cultural landscape. However, attending to their economic self-interest, they may sharply disagree on what immigration policy to vote for. In this light it is not surprising that the estimates in column 4 show that specific human capital does not have a significant effect on IM3. Instead years of education and manual skills appear to be significant.

The literature on comparative advantage between natives and immigrant groups focuses on low-education individuals (Peri and Sparber 2009, Amuedo-Dorantes and De la Rica 2009). In order to better compare our results to those studies we report estimates of our main model on two subsamples. The first subsample (column 6) contains only individuals with less than 12 years of education (57\% of the population). The second subsample (column 7) includes only individuals with 12 or more years of education (43\% of the total sample). Remarkably, the point estimates that we obtain are very similar in both cases and, in turn, very similar to our main estimates (columns 1 and 2).

Overall, the results in this section show that that our main results are robust to the particular definition of comparative advantage used as well as to the heterogeneity in the effects of education.

\section{Conclusions}

This paper has re-examined the role of labor-market competition in the determination of individual preferences over immigration. A great deal of literature has addressed this question, but has taken a very narrow view of labor market exposure to competition from immigrants. Our analysis has proposed a more comprehensive approach. In particular, we have constructed two new measures of exposure based on job-specific human capital investments and on the importance of communication-intensive tasks. Moreover, we have

\footnotetext{
${ }^{16}$ See questions B1-B3 in appendix Appendix 2.
} 
accounted for unobserved individual heterogeneity in tastes for immigration and for the resulting potential endogeneity in job search.

Overall our results provide strong support for the exposure hypothesis: individuals employed in jobs that are less exposed to competition from immigrants are relatively more pro-immigration. In particular, we have three main results.

First, we build a new instrument for individual exposure to labor market competition and show that it is highly relevant. The instrument is based on the assumption that the types of jobs available in one's regional labor market affect workers' actual job characteristics in ways that are unrelated to individual attitudes towards immigration. Second, our instrumental-variables estimates show that being employed in a job requiring a large amount of specific human capital leads to relatively more pro-immigration attitudes. The marginal effect of job-specific human capital on attitudes is much larger than the effect of formal education. Third, we show that being employed in a communication-intensive occupation also leads to more positive attitudes toward immigration. This effect is different from the effect of job-specialization and can by itself explain away the association between formal education and attitudes toward immigration.

The latter finding provides indirect support for the endogenous job specialization theory postulated by Peri and Sparber (2009). According to these authors, native workers respond to immigration by moving to occupations where they have a comparative advantage by virtue of being relatively better at communication-intensive tasks. Our results suggest that those native workers that manage to shift to the less exposed occupations display relatively more pro-immigration views than those that are unable to do so. In our view, supply-side constraints, such as the regional availability of low-exposure jobs play an important role in determining individual attitudes toward immigration. In conclusion, our findings suggest a larger role for labor-market competition as a determinant of attitudes toward immigration than previously found in the literature. 


\section{References}

Amuedo-Dorantes, C. and S. De la Rica (2009). “Complements or Substitutes? Task Specialization by Gender and Nativity in Spain.” IZA Discussion paper 4348.

Autor, David H., Frank Levy, and Richard Murnane (2003) "The Skill Content of Recent Technological Change: an Empirical Exploration.” Quarterly Journal of Economics, 118(4): 1279-1333.

Becker. G. (1993) [1964]. Human Capital. New York: Columbia University Press.

Bobo, L. and F. C. Licari (1989). "Education and Political Tolerance.” Public Opinion Quarterly, 53:285-307.

Borjas, G. J. and L. Hilton (1996). "Immigration and the welfare state: Immigrant participation in means-tested entitlement programs.” Quarterly Journal of Economics 111 (2), pp. 574-604.

Burns, P. and J. G. Gimpel (2000). "Prejudicial Stereotypes, and Public Opinion on Immigration Policy.” Political Science Quarterly, 115(2):201-225.

David Card \& John DiNardo, 2000. "Do Immigrant Inflows Lead to Native Outflows?," American Economic Review, vol. 90(2), pages 360-367, May.

Card, D., 2005. “Is the new immigration really so bad?” The Economic Journal, 115 (November), F300-F323.

Card, D., Dustmannn, C., Preston, I. (2005). “Understanding Attitudes to Immigration : The Migration and Minority Module of the first European Social Survey.” CReAM Discussion Paper No.03/05.

Côté, R. and B. H. Erickson (2009). "Untangling the Roots of Tolerance: How Forms of Social Capital Shape Attitudes toward Ethnic Minorities and Immigrants.” American Behavioral Scientist, 52:1664-1689.

Dustmannn, C., Preston, I. (2001). “Attitudes to Ethnic Minorities, Ethnic Context, and Location Decisions.” Economic Journal, 111, 353-373.

Dustmannn, C., Preston, I. (2005). "Is Immigration Good or Bad for the Economy? Analysis of Attitudinal Responses.” Research in Labour Economics, 24, 3-34.

Dustmannn, C., Preston, I. (2007). "Racial and Economic Factors in Attitudes to Immigration.” The B.E. Journal of Economic Analysis \& Policy: Vol. 7 : Iss. 1 (Advances), Article 62.

Facchini, G., and Mayda, A., 2009. "Does the Welfare State Affect Individual Attitudes toward Immigrants? Evidence across Countries.” Review of Economics and Statistics, May 2009, Vol. 91, No. 2: 295-314. 
Hainmueller, J. and M. J. Hiscox (2007). "Educated Preferences: Explaining Attitudes Toward Immigration in Europe". International Organization, 61(2):399-442

Hanson, G. H., K. Scheve, and M. Slaughter (2007). Public finance and individual preferences over globalization strategies. Economics and Politics 19 (1), pages 1-33.

Jackman, M. and M. Muha (1984). "Education and Intergroup Attitudes: Moral Enlightenment, Superficial Democratic Commitment or Ideological Refinement?" American Sociological Review, 49:751-769.

Kingston, P.W., Hubbard, R., Lapp, B., Schroeder, P and J. Wilson (2003). "Why Education Matters”. Sociology of Education, 76(1):53-70.

Lazear, E. (1995). Personnel Economics. Cambridge, Mass.: The MIT Press.

Mayda, A., (2006). "Who is against immigration? A cross-country investigation of individual attitudes toward immigrants.” Review of Economics and Statistics, 88(3): 510-530.

O'Rourke, K. H. and R. Sinnott (2006). “The determinants of individual attitudes towards immigration.” European Journal of Political Economy 22 (4), pages 838-861.

Ortega, F. (2005). “Immigration policy and skill upgrading.” Journal of Public Economics, vol. 89(9-10), pages 1841-1863, September.

Ortega, F. (2009). “Immigration, Citizenship, and the Size of Government.” Mimeo.

Peri, G., Sparber, C. (2009). “Task Specialization, Immigration and Wages” forthcoming in the American Economic Journal: Applied Economics, vol. 1(3), pages 135-69, July.

Razin, A., E. Sadka, and P. Swagel (2002). Tax burden and migration: A political economy theory and evidence. Journal of Public Economics 85.

Scheve, K. F. and M. J. Slaughter (2001). Labor market competition and individual preferences over immigration policy. Review of Economics and Statistics 83 (1), pages 133-145.

Wagner, U. and A. Zick (1995). The Relation of Formal Education to Ethnic Prejudice: Its Reliability, Validity and Explanation. European Journal of Social Psychology, 25(1), pages 41-56. 


\section{Tables and Figures}

Table 1: $\quad$ Descriptives

1a. Means by country.

\begin{tabular}{||l|c|c|c|c|c|c||}
\hline Country & IM1 & IM2 & $\begin{array}{c}\text { Education } \\
\text { years }\end{array}$ & $\begin{array}{c}\text { SHK in } \\
\text { months }\end{array}$ & Comm. skills & $\begin{array}{c}\text { Manual } \\
\text { skills }\end{array}$ \\
Portugal & & & & & & \\
Greece & 57.69 & 54.93 & 9.36 & 3.89 & 0.45 & 0.51 \\
Turkey & 59.63 & 54.17 & 12.07 & 6.64 & 0.43 & 0.53 \\
Hungary & 59.98 & 52.01 & 8.73 & 13.04 & 0.39 & 0.55 \\
Czech Republic & 63.70 & 52.37 & 12.34 & 11.56 & 0.44 & 0.55 \\
Estonia & 63.78 & 59.95 & 12.87 & 6.35 & 0.43 & 0.56 \\
Great Britain & 67.27 & 57.11 & 13.47 & 5.05 & 0.46 & 0.53 \\
Finland & 67.41 & 63.42 & 12.83 & 11.76 & 0.51 & 0.49 \\
Netherlands & 68.12 & 62.74 & 13.74 & 11.29 & 0.50 & 0.52 \\
Spain & 68.27 & 65.36 & 13.51 & 10.46 & 0.57 & 0.47 \\
Slovenia & 68.95 & 67.73 & 13.04 & 8.23 & 0.47 & 0.51 \\
France & 69.06 & 66.26 & 12.32 & 12.91 & 0.45 & 0.56 \\
Austria & 70.02 & 65.98 & 12.80 & 13.24 & 0.51 & 0.49 \\
Luxemburg & 70.58 & 65.43 & 12.78 & 6.81 & 0.49 & 0.50 \\
Belgium & 70.64 & 63.78 & 13.15 & 9.99 & 0.51 & 0.49 \\
Germany & 71.80 & 66.43 & 13.53 & 9.86 & 0.50 & 0.51 \\
Poland & 71.86 & 65.02 & 14.06 & 8.72 & 0.50 & 0.51 \\
Slovakia & 73.35 & 70.31 & 12.89 & 8.85 & 0.41 & 0.57 \\
Norway & 75.00 & 69.93 & 12.89 & 6.75 & 0.45 & 0.56 \\
Ireland & 75.35 & 70.09 & 13.92 & 9.63 & 0.50 & 0.50 \\
Switzerland & 75.47 & 71.18 & 13.40 & 7.91 & 0.48 & 0.51 \\
Denmark & 76.94 & 71.60 & 10.93 & 7.06 & 0.51 & 0.51 \\
Sweden & 76.99 & 67.44 & 14.40 & 9.51 & 0.51 & 0.50 \\
Ukraine & 80.78 & 79.08 & 13.06 & 8.79 & 0.49 & 0.52 \\
Iceland & 85.09 & 72.86 & 13.05 & 7.13 & 0.48 & 0.53 \\
min & 86.01 & 77.87 & 14.10 & 6.91 & 0.49 & 0.51 \\
mean & & & & & & \\
median & 57.69 & 52.01 & 8.73 & 3.89 & 0.39 & 0.47 \\
max & 70.95 & 65.32 & 12.77 & 8.89 & 0.48 & 0.52 \\
\hline & 70.58 & 65.98 & 13.04 & 8.79 & 0.49 & 0.51 \\
& 86.01 & 79.08 & 14.40 & 13.24 & 0.57 & 0.57 \\
\hline
\end{tabular}

Notes: Sorted from less to more pro-immigration based on the main dependent variable (IM1). SHK (specific-human capital) in months. See appendix for definitions of all variables. 
1b. Summary main variables

\begin{tabular}{||l|c|c|c|c|c||}
\hline Variable & Obs & Mean & Std. Dev. & Min & Max \\
IM1 & 20121 & 70.87 & 21.23 & 25 & 100 \\
yearsedu & 20619 & 12.84 & 3.58 & 0 & 25 \\
shk_months & 16747 & 8.84 & 13.90 & 0.02 & 73 \\
shk_days & 16747 & 265.12 & 417.14 & 0.50 & 2190 \\
comm & 20123 & 0.48 & 0.22 & 0.09 & 0.95 \\
manual & 20123 & 0.52 & 0.17 & 0.24 & 0.86 \\
country & & & & & \\
region & 20619 & 12.16 & 7.23 & 1 & 25 \\
age & 20618 & 138.95 & 75.80 & 1 & 273 \\
female & 20619 & 41.64 & 11.12 & 18 & 2 \\
d_children & 20596 & 1.46 & 0.50 & 1 & 1 \\
d_rural & 20619 & 0.53 & 0.50 & 0 & 1 \\
d_motherfb & 20619 & 0.37 & 0.48 & 0 & 10 \\
& 20619 & 0.07 & 0.26 & 0 & 10 \\
ideology & 20619 & 5.11 & 1.97 & 0 & 10 \\
religiosity & 20467 & 4.39 & 2.87 & 0 & 7 \\
happy & 20532 & 7.41 & 1.80 & 0 & 1 \\
trust & 20609 & 5.20 & 1.96 & 0 & 1.96 \\
social capital & 20619 & 4.92 & 1.48 & & 1 \\
\hline \hline
\end{tabular}

Source: ESS 2004. 
Table 2: $\quad$ The top 10 occupations according to average years of education, average job-specific human capital (job-learning time), average communicational intensity scores and average manual intensity scores.

\begin{tabular}{|c|c|c|c|}
\hline Education (in years) & Mean & Job-specific human capital (in months) & Mean \\
\hline Physicists, Chemists and related prof. & 20.8 & Riggers and cable splicers & 73 \\
\hline Medical Doctors & 19.4 & Photographic-products machine operators & 42.6 \\
\hline Biologists, botanists, zoologists \& related & 18.7 & Farming and forestry advisers-technicians & 39.6 \\
\hline Higher education teaching professionals & 18.4 & Tobacco preparers and tobacco products makers & \\
\hline & & & 38.6 \\
\hline Judges & 17.8 & Aircraft engine mechanics and fitters & 38.4 \\
\hline Veterinarians & 17.6 & Wood processing and paper-making plant operators & \\
\hline Lawyers & 17.6 & $\begin{array}{l}\text { Physical, mathematical and engineering science } \\
\text { professionals }\end{array}$ & 36.6 \\
\hline Dentists & 17.4 & General managers of small enterprises & 31.9 \\
\hline Psychologists & 17.4 & Upholsterers and related workers & 27.6 \\
\hline Mathematicians and related professionals & 17.1 & $\begin{array}{l}\text { Production and operations managers in agriculture, } \\
\text { hunting, forestry and fishing }\end{array}$ & 26.5 \\
\hline Communicational skills & Score & Manual skills & Score \\
\hline Legislators and senior officials & 0,950 & Precision handicraft \& printing workers & 0,860 \\
\hline Corporate managers & 0,807 & Other craft workers & 0,841 \\
\hline Life science $\&$ health professionals & 0,760 & Metal machinery workers & 0,830 \\
\hline Other professionals & 0,759 & Machine operators and assemblers & 0,793 \\
\hline Teaching professionals & 0,715 & Stationary plant operators & 0,756 \\
\hline General managers & 0,711 & Extraction and building trade workers & 0,741 \\
\hline Physical, math.\& engineering sci. prof. & 0,687 & Agriculture \& fishery unskilled occupations & 0,708 \\
\hline Other associate professionals & 0,657 & Physical \& engineering associate profess. & 0,693 \\
\hline Life science $\&$ health assoc. profess. & 0,638 & Drivers and mobile plant operators & 0,693 \\
\hline Teaching associate professionals & 0,560 & Skilled agricultural and fishery workers & 0,679 \\
\hline
\end{tabular}

Notes: Average years of education in occupation and average job-learning time in occupations calculated using ISCO-88 4-digit coding. Average communication intensity and manual intensity scores using ISCO-88 2-digit coding.

Source: ESS 2004 and O*NET. 
Table 3: $\quad$ First-stage regressions

\begin{tabular}{|c|c|c|c|c|c|c|}
\hline $\begin{array}{l}\text { Column } \\
\text { Dep. var. }\end{array}$ & $\begin{array}{c}(1) \\
\text { SHK }\end{array}$ & $\begin{array}{c}(2) \\
\text { COMM. }\end{array}$ & $\begin{array}{c}(3) \\
\text { MANUAL }\end{array}$ & $\begin{array}{c}(4) \\
\text { SKH }\end{array}$ & $\begin{array}{c}(5) \\
\text { COMM. }\end{array}$ & $\begin{array}{c}(6) \\
\text { MANUAL }\end{array}$ \\
\hline avSHK_r & $0.92^{* * *}$ & & & $0.92 * * *$ & $-0.0014 * *$ & $0.0012^{* *}$ \\
\hline tstat & 47.99 & & & 41.78 & -2.44 & 2.73 \\
\hline avCOMM_r & & $0.56^{* * *}$ & & $-7.792 * * *$ & $0.58^{* * *}$ & \\
\hline & & 19.38 & & -4.75 & 19.55 & \\
\hline avMANUAL_r & & & $0.69^{* * *}$ & & & $0.68^{* * *}$ \\
\hline tstat & & & 28.07 & & & 23.81 \\
\hline F stat & 2303.04 & 375.58 & 787.92 & 895.79 & 191.38 & 283.37 \\
\hline Observations & 16369 & 19632 & 19632 & 16029 & 16029 & 16029 \\
\hline
\end{tabular}

The columns below use a restricted sample: only individuals in regions with at least 25 observations.

\begin{tabular}{|c|c|c|c|}
\hline $\begin{array}{l}\text { Column } \\
\text { Dep. var. }\end{array}$ & $\begin{array}{l}\text { (1b) } \\
\text { SHK }\end{array}$ & $\begin{array}{c}(2 \mathrm{~b}) \\
\text { comM. }\end{array}$ & $\begin{array}{c}(3 b) \\
\text { MANUAL }\end{array}$ \\
\hline $\begin{array}{l}\text { avSHK_r } \\
\text { tstat } \\
\text { avCOMM_r } \\
\text { tstat } \\
\text { avMANUAL_r } \\
\text { tstat }\end{array}$ & $\begin{array}{c}0.92 * * * \\
42.33\end{array}$ & $\begin{array}{c}0.55 * * * \\
18.13\end{array}$ & $\begin{array}{c}0.69 * * * \\
25.71\end{array}$ \\
\hline F stat & 1792 & 329 & 661 \\
\hline Observations & 15588 & 18683 & 18683 \\
\hline
\end{tabular}

Notes:

- Standard errors clustered by region and robust to heteroskedasticity.

- *** $\mathrm{p}<0.01, * * \mathrm{p}<0.05, * \mathrm{p}<0.1 * * *$

- All specifications include country-specific dummies, years of education, controls for gender, age, age squared, as well as dummies for children, rural, and foreign-born mother.

- The F statistic refers to the null of jointly zero coefficients. 
Table 4: $\quad$ Job-specific human capital (SHK).

\begin{tabular}{||l|c|c|c|c|c|c||}
\hline \hline Column & $(1)$ & $(2)$ & $(3)$ & $(4)$ & $(5)$ & $(6)$ \\
Estimation & OLS & OLS & OLS & OLS & IV & IV \\
\hline \multirow{4}{*}{ yearsedu } & & & & & & \\
& $1.066^{* * *}$ & $1.072^{* * *}$ & $0.933^{* * *}$ & $1.086^{* * *}$ & $0.943^{* * *}$ & $0.808^{* * *}$ \\
& {$[0.0572]$} & {$[0.0612]$} & {$[0.0599]$} & {$[0.0579]$} & {$[0.0911]$} & {$[0.0910]$} \\
& & 0.0158 & 0.0141 & 0.0107 & $0.224^{*}$ & $0.221^{*}$ \\
SHK & & {$[0.0119]$} & {$[0.0117]$} & {$[0.0119]$} & {$[0.116]$} & {$[0.116]$} \\
female & & & & & & \\
age & $-0.830^{* * *}$ & -0.555 & $-0.955^{* * *}$ & $-0.637 *$ & 0.372 & -0.0616 \\
& {$[0.316]$} & {$[0.351]$} & {$[0.345]$} & {$[0.353]$} & {$[0.618]$} & {$[0.595]$} \\
age2 & -0.00289 & -0.0700 & -0.0493 & -0.0593 & -0.132 & -0.118 \\
d_children & {$[0.108]$} & {$[0.116]$} & {$[0.113]$} & {$[0.117]$} & {$[0.121]$} & {$[0.120]$} \\
& 0.000204 & 0.00101 & 0.000637 & 0.000870 & 0.00141 & 0.00110 \\
d_rural & {$[0.00129]$} & {$[0.00140]$} & {$[0.00138]$} & {$[0.00140]$} & {$[0.00142]$} & {$[0.00141]$} \\
& -0.0214 & -0.106 & -0.156 & -0.0847 & -0.280 & -0.327 \\
d_motherfb & {$[0.306]$} & {$[0.327]$} & {$[0.327]$} & {$[0.332]$} & {$[0.346]$} & {$[0.346]$} \\
& $-2.168^{* * *}$ & $-2.041^{* * *}$ & $-2.236 * * *$ & $-1.585 * * *$ & $-1.967 * * *$ & $-2.154 * * *$ \\
& {$[0.333]$} & {$[0.354]$} & {$[0.363]$} & {$[0.369]$} & {$[0.353]$} & {$[0.362]$} \\
Observations & $2.947 * * *$ & $2.663^{* * *}$ & $2.818^{* * *}$ & $2.227 * * *$ & $2.618^{* * *}$ & $2.751^{* * *}$ \\
R-squared & {$[0.686]$} & {$[0.728]$} & {$[0.733]$} & {$[0.713]$} & {$[0.712]$} & {$[0.716]$} \\
\hline Fixed effects & 20098 & 16369 & 16232 & 16369 & 16369 & 16232 \\
Attitudes & 0.132 & 0.126 & 0.151 & 0.159 & 0.108 & 0.134 \\
\hline
\end{tabular}

Notes:

- Standard errors clustered by region and robust to heteroskedasticity.

- Standard errors in square brackets. ${ }^{* * *} \mathrm{p}<0.01,{ }^{* *} \mathrm{p}<0.05{ }^{*} \mathrm{p}<0.1^{* * *}$

- Dependent variable is IM1, the answer to the question "Do you think there should be no more immigration, a few more immigrants, some more immigrants, or many more immigrants?” Question refers to immigrants belonging to the current majority group.

- Measures of Individual Values: Ideology, Religiosity, Happiness, Trust, and social capital. 
Table 5: Communication intensity in current occupation.

\begin{tabular}{||l|c|c|c|c|c|c||}
\hline \hline Column & $(1)$ & $(2)$ & $(3)$ & $(4)$ & $(5)$ & $(6)$ \\
Estimation & OLS & OLS & OLS & OLS & IV & IV \\
\hline & & & & & & \\
yearsedu & $1.066^{* * *}$ & $0.714^{* * *}$ & $0.607^{* * *}$ & $0.744^{* * *}$ & 0.218 & 0.114 \\
& {$[0.0572]$} & {$[0.0586]$} & {$[0.0577]$} & {$[0.0543]$} & {$[0.310]$} & {$[0.306]$} \\
comm. & & $11.18^{* * *}$ & $10.46^{* * *}$ & $10.68^{* * *}$ & $27.06^{* * *}$ & $26.46^{* * *}$ \\
& & {$[0.908]$} & {$[0.908]$} & {$[0.889]$} & {$[10.04]$} & {$[10.07]$} \\
Observations & 20098 & 19632 & 19431 & 19632 & 19632 & 19431 \\
R-squared & 0.132 & 0.141 & 0.165 & 0.170 & 0.122 & 0.145 \\
\hline Fixed effects & country & country & country & region & country & country \\
Attitudes & no & no & yes & no & no & yes \\
\hline \hline
\end{tabular}

Notes:

- Standard errors clustered by region and robust to heteroskedasticity.

- Standard errors in square brackets. ${ }^{* * *} \mathrm{p}<0.01,{ }^{* *} \mathrm{p}<0.05,{ }^{*} \mathrm{p}<0.1^{* * *}$

- Dependent variable is IM1, the answer to the question "Do you think there should be no more immigration, a few more immigrants, some more immigrants, or many more immigrants?” Question refers to immigrants belonging to the current majority group.

- All specifications include country-specific fixed effects, dummies for children, rural, and foreignborn mother. Also controls for gender, age, and age squared.

- Measures of Attitudes: Ideology, Religiosity, Happiness, Trust, and social capital. 
Table 6: Interaction between the skill determinants of attitudes toward immigration.

\begin{tabular}{||l|c|c|c|c|c||}
\hline \hline Dep. Var: IM1 & $(1)$ & $(2)$ & $(3)$ & $(4)$ & $(5)$ \\
Estimation & IV & IV & IV & IV & IV \\
\hline & & & & & \\
yearsedu & $1.066^{* * *}$ & $0.943^{* * *}$ & 0.228 & 0.0962 & 0.174 \\
& {$[0.0570]$} & {$[0.0911]$} & {$[0.334]$} & {$[0.326]$} & {$[0.208]$} \\
& & & & & \\
SHK & & $0.224^{*}$ & $0.209^{*}$ & $0.203^{*}$ & $0.233^{* *}$ \\
& & {$[0.116]$} & {$[0.115]$} & {$[0.116]$} & {$[0.116]$} \\
Comm. & & & & \\
& & & $21.88^{* *}$ & $22.14^{* *}$ & \\
Manual & & & {$[9.631]$} & {$[9.506]$} & \\
& & & & & \\
& & & & & \\
& & & & & \\
Observations & 20098 & 16369 & 16029 & 15897 & 16029 \\
R-squared & 0.132 & 0.108 & 0.107 & 0.13 & 0.068 \\
Attitudes & no & no & no & yes & yes \\
\hline \hline
\end{tabular}

Notes:

- Standard errors clustered by region and robust to heteroskedasticity.

- Standard errors in square brackets. ${ }^{* * *} \mathrm{p}<0.01,{ }^{* *} \mathrm{p}<0.05,{ }^{*} \mathrm{p}<0.1^{* * *}$

- Dependent variable is IM1, the answer to the question "Do you think there should be no more immigration, a few more immigrants, some more immigrants, or many more immigrants?” Question refers to immigrants belonging to the current majority group.

- All specifications include country-specific fixed effects, dummies for children, rural, and foreignborn mother. Also controls for gender, age, and age squared.

- Measures of Attitudes: Ideology, Religiosity, Happiness, Trust, and social capital. 
Table 7: $\quad$ Robustness.

\begin{tabular}{||l|c|c|c|c|c|c||}
\hline \hline Column & $(1)$ & $(2)$ & $(3)$ & $(4)$ & $(5)$ & $(6)$ \\
Estimation & IV & IV & IV & IV & IV & IV \\
Dep. var. & IM1 & IM1 & IM2 & IM3 & IM1 & IM1 \\
\hline \multirow{3}{*}{ yearsedu } & 0.228 & 0.298 & $0.359^{* *}$ & $0.548^{* * *}$ & 0.000731 & 0.248 \\
& {$[0.334]$} & {$[0.211]$} & {$[0.166]$} & {$[0.173]$} & {$[0.175]$} & {$[0.342]$} \\
& & & & & & \\
SHK & $0.209^{*}$ & $0.239^{* *}$ & $0.183^{*}$ & 0.077 & 0.245 & $0.266^{*}$ \\
& {$[0.115]$} & {$[0.114]$} & {$[0.0971]$} & {$[0.0932]$} & {$[0.157]$} & {$[0.139]$} \\
& & & & & & \\
Comm. & $21.88^{* *}$ & & & & & \\
& {$[9.631]$} & & & & & \\
& & & & & & \\
Manual & & $-38.89 * * *$ & $-43.36^{* * *}$ & $-44.02^{* * *}$ & $-30.47 * *$ & $-50.65 * * *$ \\
& & {$[11.24]$} & {$[8.916]$} & {$[9.581]$} & {$[12.15]$} & {$[17.23]$} \\
& & & & & & \\
\hline Obs. & 16029 & 16029 & 15801 & 15331 & 7858 & 8171 \\
R-squared & 0.107 & 0.068 & 0.087 & 0.102 & 0.081 & 0.04 \\
\hline \hline
\end{tabular}

Notes:

(1) Baseline. IV in our preferred specification.

(2) Manual index replaces communication intensity index.

(3) Both manual and communication intensity indices.

(4) Dependent variable is average of the three questions regarding the level of immigration preferred by the respondent (IM2). See appendix.

(5) Dependent variable is average of the three questions regarding the general view on immigration (IM3). See appendix.

(6) Baseline on subsample of individuals with less than 12 years of education ( $57 \%$ sample).

(7) Baseline on subsample of individuals with more than 12 years of education (43\% sample).

- All estimates in the table are IV. Standard errors clustered by region and robust to heteroskedasticity. Standard errors in square brackets. ${ }^{* * *} \mathrm{p}<0.01,{ }^{* *} \mathrm{p}<0.05,{ }^{*} \mathrm{p}<0.1^{* * *}$

- All specifications include country-specific fixed effects, dummies for children, rural, and foreignborn mother. Also controls for gender, age, and age squared. 


\section{Appendix}

\section{Appendix 1. Observations by country.}

\begin{tabular}{|c|c|c|c|}
\hline country & Freq. & Percent & Cum. \\
\hline AT & 1,751 & 5.16 & 5.16 \\
\hline $\mathrm{BE}$ & 1,305 & 3.85 & 9.01 \\
\hline $\mathrm{CH}$ & 1,378 & 4.06 & 13.07 \\
\hline $\mathrm{CZ}$ & 2,123 & 6.26 & 19.33 \\
\hline $\mathrm{DE}$ & 2,026 & 5.97 & 25.30 \\
\hline DK & 1,135 & 3.35 & 28.65 \\
\hline $\mathrm{EE} \mid$ & 1,195 & 3.52 & 32.17 \\
\hline ES | & 1,147 & 3.38 & 35.55 \\
\hline FI & 1,494 & 4.40 & 39.96 \\
\hline FR | & 1,297 & 3.82 & 43.78 \\
\hline GB & 1,321 & 3.89 & 47.67 \\
\hline GR & 1,535 & 4.53 & 52.20 \\
\hline $\mathrm{HU}$ & 1,156 & 3.41 & 55.61 \\
\hline IE & 1,686 & 4.97 & 60.58 \\
\hline IS & 465 & 1.37 & 61.95 \\
\hline LU | & 861 & 2.54 & 64.49 \\
\hline NL & 1,364 & 4.02 & 68.51 \\
\hline NO & 1,376 & 4.06 & 72.56 \\
\hline PL | & 1,404 & 4.14 & 76.70 \\
\hline PT & 1,360 & 4.01 & 80.71 \\
\hline $\mathrm{SE}$ & 1,431 & 4.22 & 84.93 \\
\hline SI | & 1,055 & 3.11 & 88.04 \\
\hline SK | & 1,174 & 3.46 & 91.50 \\
\hline TR & 1,497 & 4.41 & 95.91 \\
\hline UA & 1,386 & 4.09 & 100.00 \\
\hline Total & 33,922 & 100.00 & \\
\hline
\end{tabular}

Sample: Citizens age 18-64. 


\section{Appendix 2. Definition dependent variable.}

We consider three variations of our dependent variable, the respondent's views toward immigration. In all cases higher values are associated to a more pro-immigration stance.

Our main dependent variable is IM1. It is based on the following question:

B35 CARD 14 Now, using this card, to what extent do you think [country] should ${ }^{17}$ allow people of the same race or ethnic group as most [country's] people to come and live here ${ }^{18}$ ?

Allow many to come and live here 1

$\begin{array}{ll}\text { Allow some } & 2 \\ \text { Allow a few } & 3 \\ \text { Allow none } & 4 \\ \text { (Don’t know) } & 8\end{array}$

We re-scale the values to range between 25 (allow none) to 100 (allow many).

The second variation of our dependent variable is IM2. This variable is a simple average of questions B35, B36 and B37. It also ranges from 25 to 100.

B36 STILL CARD 14 How about people of a different race or ethnic group from most [country] people? Still use this card.

B37 STILL CARD 14 How about people of a poorer countries outside Europe? Use the same card.

\footnotetext{
17 "Should" in the sense of 'ought to'; not in the sense of 'must'.

18 "Here" = country throughout these questions.
} 
The third variation (IM3) is based on three questions regarding the respondent's general view on immigration. Unlike the previous set of questions, questions B38-B40 are what political scientists call sociotropic, that is, they refer to the effects of immigration for the country as a whole and hence we believe they are less clearly related to the effects of immigration on the respondent's individual labor market outcomes. As before, we take a simple average and re-scale the variable to take on a maximum value of 100 .

B38 CARD 15 Would you say it is generally bad or good for [country]'s economy that people come to live here from other countries? Please use this card.

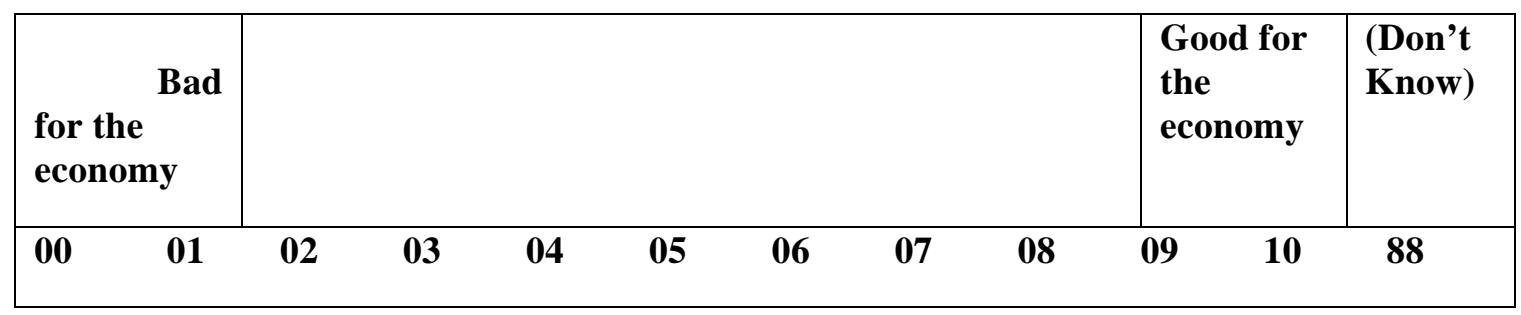

B39 CARD 16 And, using this card, would you say that [country]'s cultural life is generally undermined or enriched by people coming to live here from other countries?

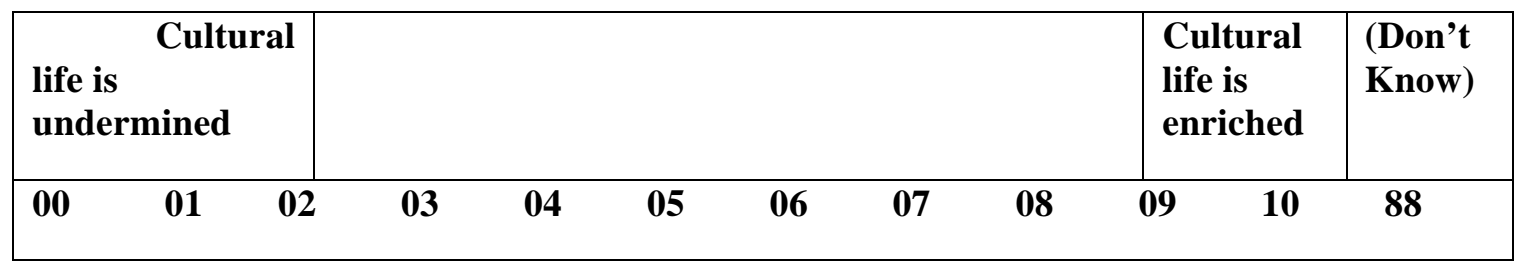

B40 CARD 17 Is [country] made a worse or a better place to live by people coming to live here from other countries? Please use this card.

\begin{tabular}{|l|lllllllll|l|l|}
\hline $\begin{array}{l}\text { Worse } \\
\text { place to } \\
\text { live }\end{array}$ & & & & & & & & & & $\begin{array}{l}\text { Better } \\
\text { place to } \\
\text { live }\end{array}$ & $\begin{array}{l}\text { (Don't } \\
\text { Know) }\end{array}$ \\
\hline 00 & 01 & 02 & 03 & 04 & 05 & 06 & 07 & 08 & 09 & 10 & 88 \\
\hline
\end{tabular}




\section{Appendix 3. Tabulation main variables}

APP3.1. Dependent variable (IM1)

Original question in ESS2004:

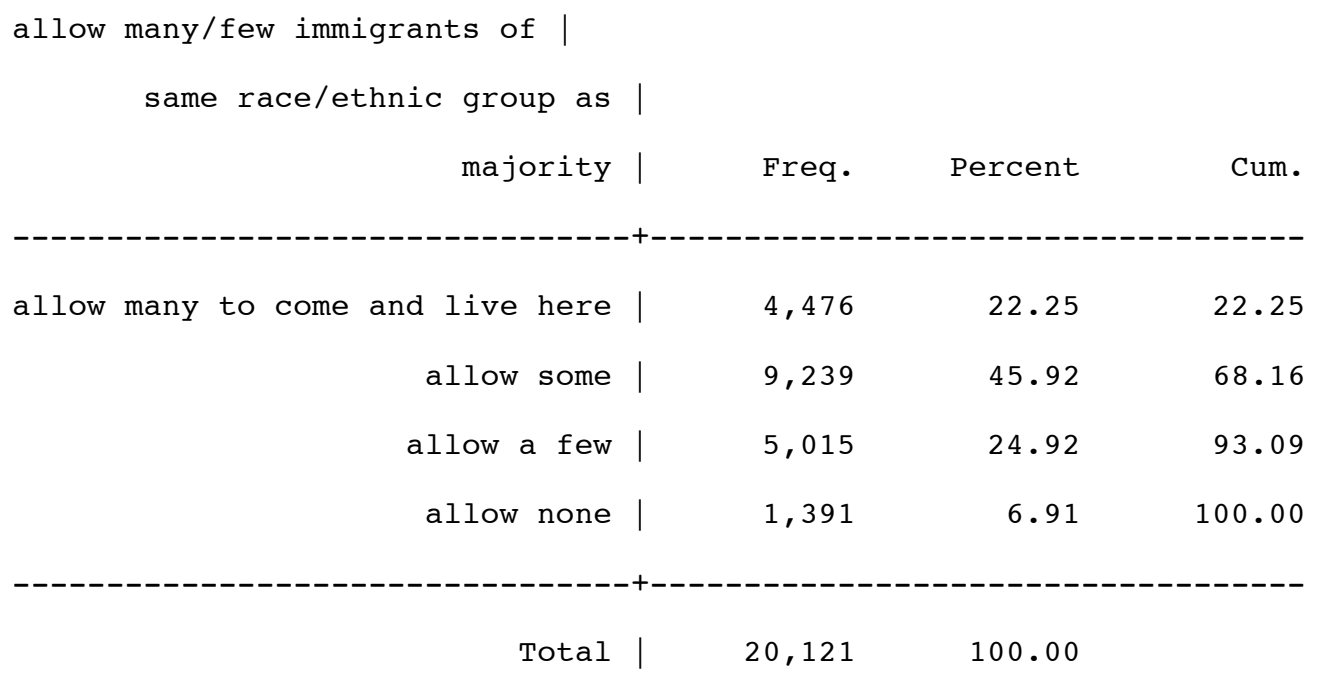

Our transformation:

$\begin{array}{rrrr}\text { imdv1 | } & \text { Freq. } & \text { Percent } & \text { Cum. } \\ 25 & 1,391 & 6.91 & 6.91 \\ 50 & 5,015 & 24.92 & 31.84 \\ 75 & 9,239 & 45.92 & 77.75 \\ 100 & 4,476 & 22.25 & 100.00 \\ & & & \\ \text { Total | } & 20,121 & 100.00 & \end{array}$


APP3.2. Job-specific human capital

Original question in ESS2004:

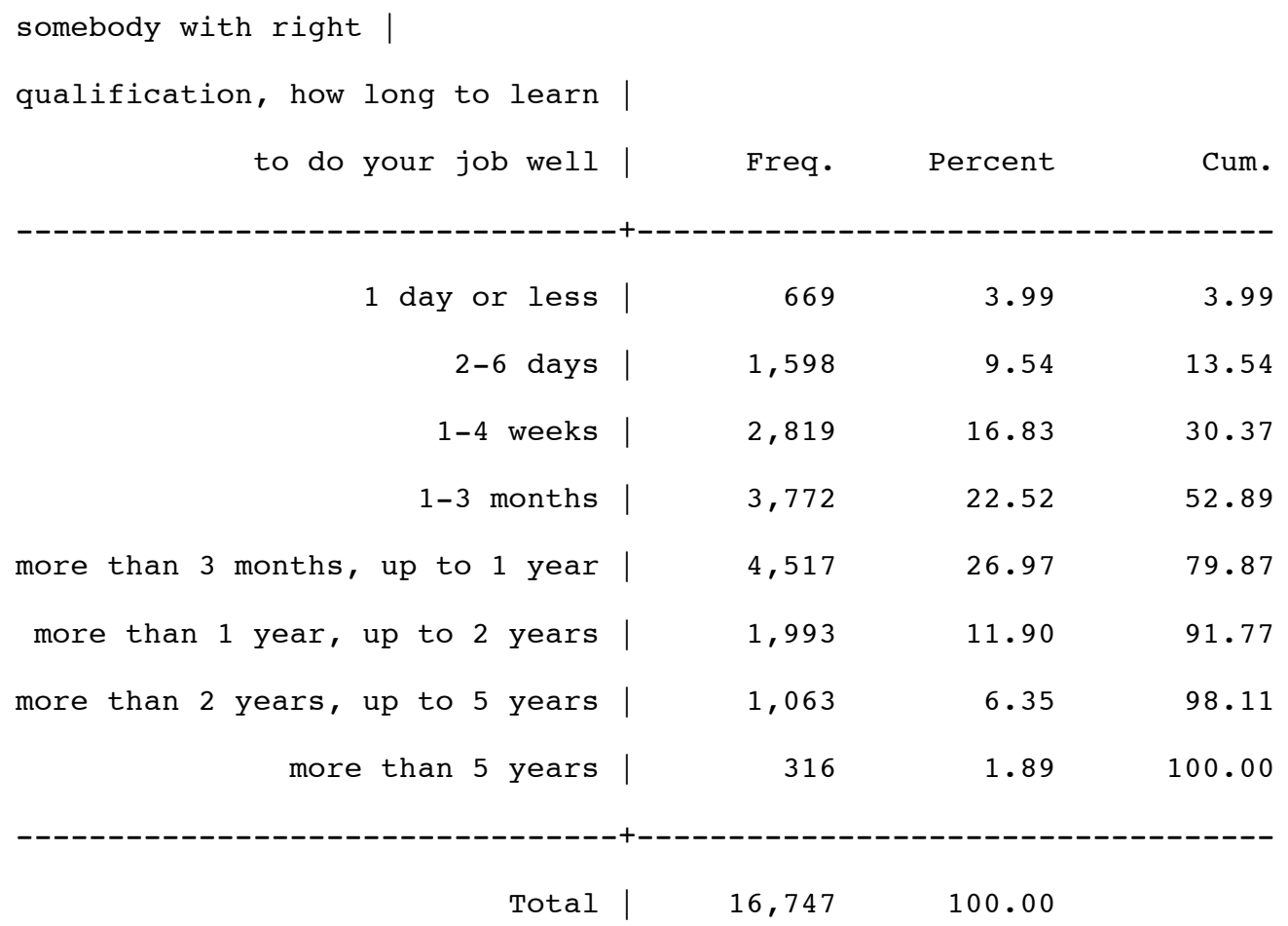

Our transformation (in months):

\begin{tabular}{|c|c|c|c|}
\hline shk_months | & Freq. & Percent & Cum. \\
\hline .0166667 & 669 & 3.99 & 3.99 \\
\hline .1333333 & 1,598 & 9.54 & 13.54 \\
\hline .5833333 & 2,819 & 16.83 & 30.37 \\
\hline 21 & 3,772 & 22.52 & 52.89 \\
\hline 7.5 & 4,517 & 26.97 & 79.87 \\
\hline 18.25 & 1,993 & 11.90 & 91.77 \\
\hline 42.58333 & 1,063 & 6.35 & 98.11 \\
\hline $73 \mid$ & 316 & 1.89 & 100.00 \\
\hline Total & 16,747 & 100.0 & \\
\hline
\end{tabular}


APP3.3. Communication intensity index

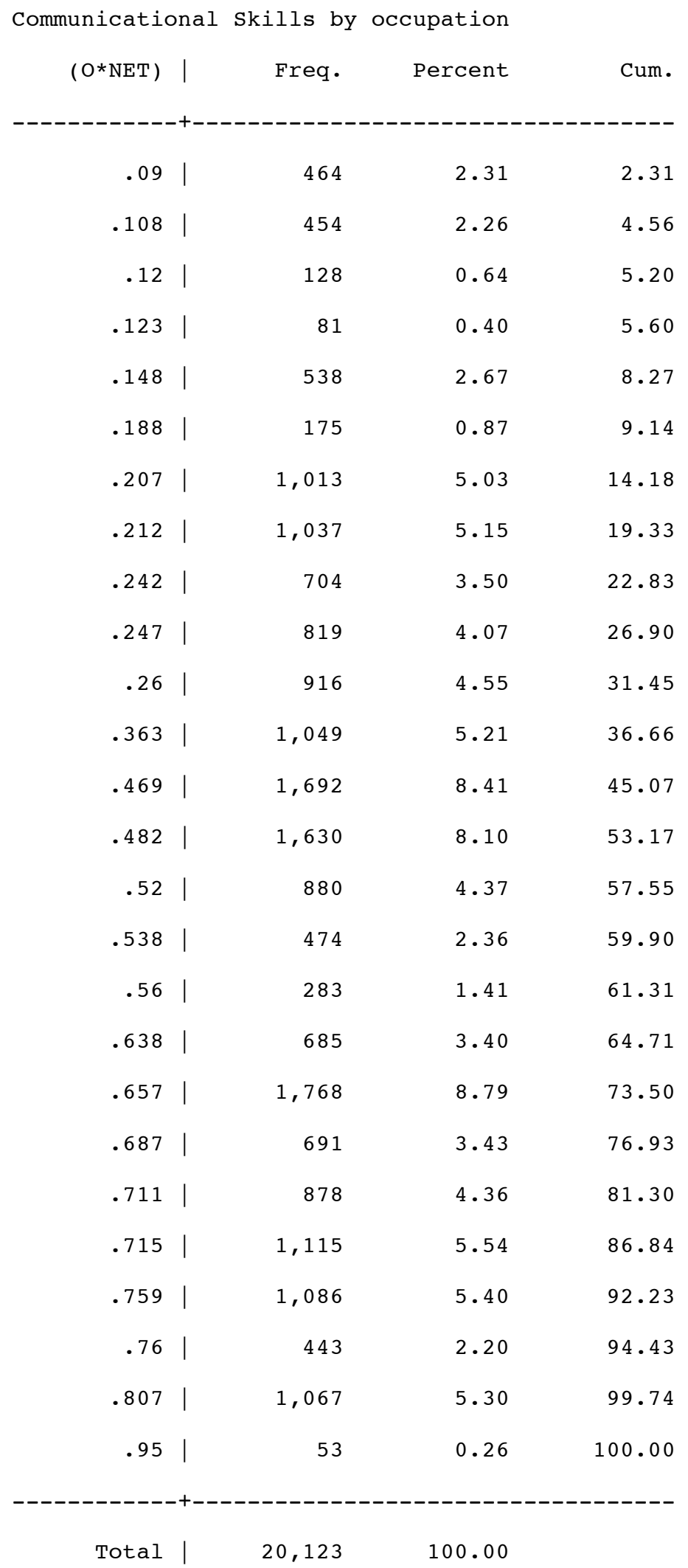


APP3.4. Manual dexterity index

Manual skills by occupation (O*NET) | Freq. Percent Cum.

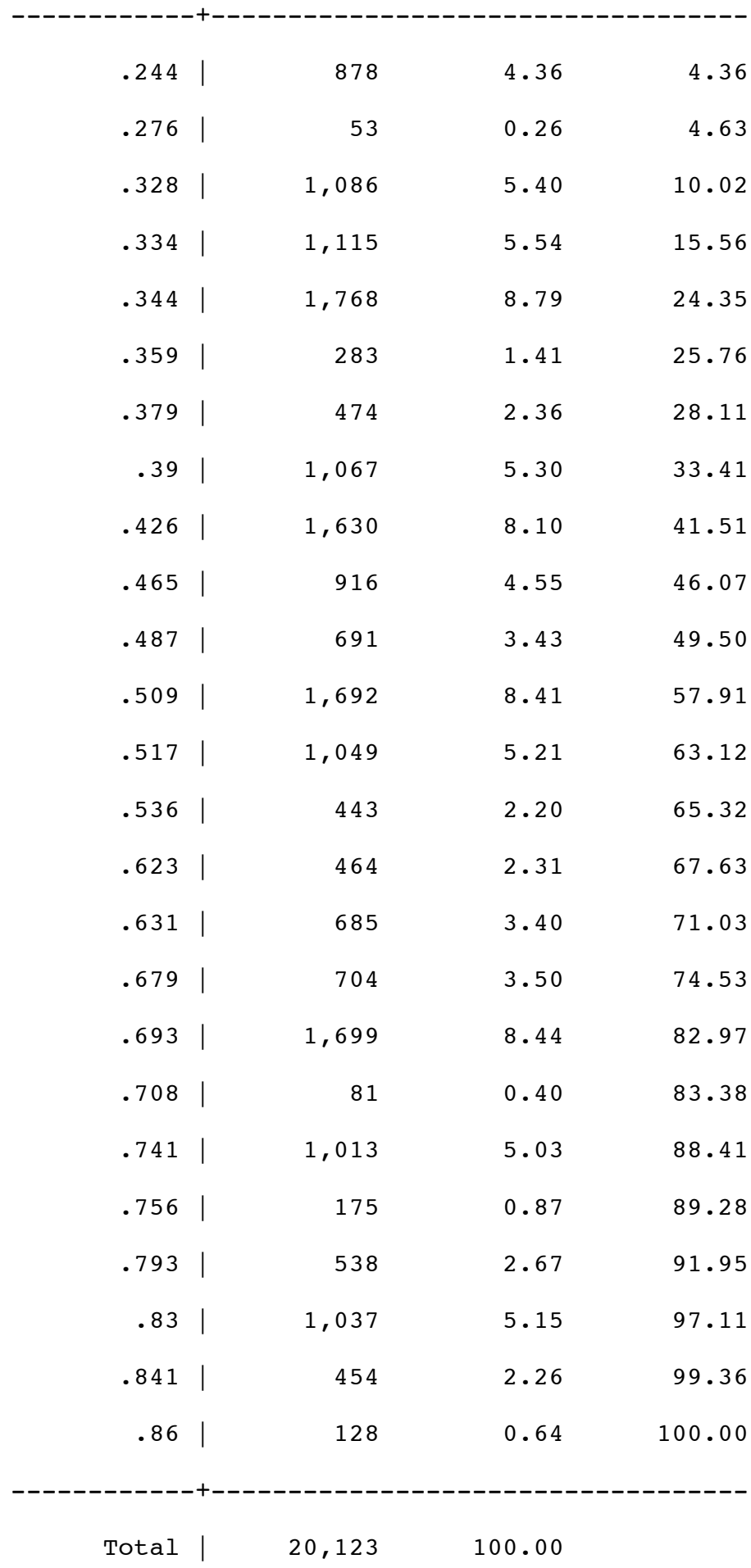


Appendix 4. Construction indices for communication and manual intensities

O*NET reports descriptors for up to 965 different occupations when occupations are coded at the maximum level of detail (i.e. 4-digits). Yet US occupations are much harder to match into the International System of Occupational Coding, ISCO-88, when they are coded in 4digits. Hence we use an $\mathrm{O}$ NET dataset where occupations are coded at 3 digits $(\mathrm{N}=449)$. Moreover, crosswalks from the occupational coding system deployed by O*NET and ISCO-88 have so far only been available for a 3-digit into 2-digit conversion. ISCO-88 at 2-digits groups the $449 \mathrm{O} * \mathrm{NET}$ occupations into 26 broader occupational categories.

For the construction of our indices we proceed as follows: First, informed by factor analysis, we compute communicational intensity and manual intensity scores using the 3digit $\mathrm{O}$ *NET dataset. This procedure, which is described in detail below, assigns both a communicational intensity and a manual intensity score to each of the 449 occupations of the O*NET dataset. Secondly, using the crosswalk kindly provided by Sara De la Rica and Catalina Amuedo-Dorantes, we convert our O*NET occupations into their ISCO-88 2-digit equivalents. All descriptors, as well as our two measures of communication and manual skill intensity are converted into 2-digits by averaging the scores of all 3-digit occupations belonging to the same 2-digit category. Finally, we match this information to the ESS data. Our final skill measures are thus much less refined than it would be in principle possible, should we have a 3-to-3-digit converter (or even a 4-to-4). Information is undoubtedly loss in the matching process. For example, O*NET provides detailed skill descriptors for "Elevator installers and repairers", yet in order to match this US 3-digit occupation into the ESS, we need to average these skill descriptors with those of all other occupations belonging to the same ISCO-88 2-digit equivalent, which is "Metal, machinery and related trade workers". Loss of information is unavoidable giving our matching procedure.

The construction of the skill indices in $\mathrm{O}$ NET was informed by exploratory factor analysis. Principal-component factor analysis with orthogonal varimax rotation identified 10 different factors out of the 277 skill descriptors in the O*NET dataset (at 3-digits). The first factor accounted for 25.6 of the variance. Skill-descriptors with rotated factor loadings higher than 0.6 in this first factor included both skills directly involved in communication 
(i.e. oral comprehension, oral expression, written comprehension, written expression, speech recognition, and speech clarity) as well as skills relating to abstract thinking (i.e. fluency of ideas, originality, problem sensitivity, deductive and inductive reasoning, information ordering, category flexibility, memorization, etc.). Our communication intensity measure only uses the 6 former skills, since there is no reason to suppose any comparative advantage of natives in the latter. The index is the result of averaging the taskimportance and the observed-ability scores of these 6 communicational skills for each of the 449 occupations $^{19}$ — which were later condensed into their ISCO-88 2-digit equivalents. Although we only focus on direct communicational skills, it must be noted that occupations were communicational skills are on demand tend to be those that also require abstract thinking.

The fourth factor of the principal component analysis identified 7 different skills/abilities relating to physical dexterity (i.e. visualization, arm-hand steadiness, manual dexterity, finger dexterity, control precision, wrist-finger speed and visual color discrimination). These 7 skills correspond to the descriptors with rotated factor scores higher that 0.55 . The manual dexterity factor accounted for 10.1 per cent of the skill variance. The manual intensity index is constructed by averaging the task-importance and observed ability scores of these 7 skills.

\footnotetext{
${ }^{19}$ For each skill involved in any given occupation, O*NET experts evaluate 2 different dimensions: 1) how important is this given skill/ability for the occupation and 2) the average observed levels of such skill in the occupation. Both dimensions correlate very highly, as can be expected. Factor analysis and hence our indices use both type of descriptors so for each of the skills involved in our indices we actually average 2 different descriptors, one referring to task-importance and the other referring to observed levels.
} 
APP4.1 The top 10 O*NET occupations (3 digits) with highest communicational-intensity and manual intensity scores.

\begin{tabular}{|lr|lr|}
\hline \multicolumn{1}{|c|}{ Communicational skills } & Score & \multicolumn{1}{c|}{ Manual skills } & Score \\
\hline Public Relations Specialists & 0.96 & Electricians & 0.97 \\
Chief executives and legislators & 0.95 & Cabinetmakers and Bench Carpenters & 0.97 \\
Clergy & 0.95 & Jewelers and Precious Stone Workers & 0.97 \\
Human Resources Managers & 0.93 & Structural Iron and Steel Workers & 0.96 \\
Social and Community Service & 0.93 & Engine and Other Machine Assemblers & 0.95 \\
Managers & 0.93 & Electronic Equip. Installers \& Repairers Motor Vehicles & 0.95 \\
Speech-Language Pathologists & 0.92 & Packaging and Filling Machine Operators and Tenders & 0.95 \\
& 0.92 & Electronic Home Entertainment Equipment Installers and & 0.95 \\
Advertising and Promotions Managers & & Repairers & 0.94 \\
Paralegals and Legal Assistants & 0.92 & Electric Motor, Power Tool, and Rlated Repairers & 0.94 \\
Podiatrists & & 0.92 & Tool Grinders, Filers, and Sharpeners \\
Sales Engineers & & &
\end{tabular}

